\title{
REVIEW
}

\section{Euthymia in Diabetes: Clinical Evidence and Practice- Based Opinion from an International Expert Group}

\author{
Sanjay Kalra · A. K. Das · M. P. Baruah · A. G. Unnikrishnan · Arundhati Dasgupta - Parag Shah • \\ Rakesh Sahay · Rishi Shukla · Sambit Das · Mangesh Tiwaskar · G. Vijayakumar • Manoj Chawla • \\ Fatimah Eliana · Ketut Suastika • Abbas Orabi · Aly Ahmed Abdul Rahim • Andrew Uloko • \\ Roberta Lamptey · Nancy Ngugi · Silver Bahendeka · Abdurezak Ahmed Abdela · Fariduddin Mohammed • \\ Mohammed Faruque Pathan · Muhammed Hafizur Rahman · Faria Afsana · Shajada Selim • \\ Muaz Moosa · Moosa Murad · Pradeep Krishna Shreshtha · Dina Shreshtha · Mimi Giri · \\ Wiam Hussain · Ahmed Al-Ani · Kaushik Ramaiya · Surender Singh • Syed Abbas Raza • \\ Than Than Aye $\cdot$ Chaminda Garusinghe $\cdot$ Dimuthu Muthukuda Muditha Weerakkody • \\ Shyaminda Kahandawa · Charlotte Bavuma · Sundeep Ruder · Koy Vanny · Manish Khanolkar • \\ Leszek Czupryniak
}

Received: February 23, 2019 / Published online: April 22, 2019

(C) The Author(s) 2019

\section{ABSTRACT}

Aim: To develop an evidence-based expert group opinion on various types of euthymia

Enhanced Digital Features To view enhanced digital features for this article go to https://doi.org/10.6084/ m9.figshare.7946273.

S. Kalra $(\bowtie)$

Department of Endocrinology, Bharti Hospital and BRIDE, Karnal, Haryana, India

e-mail: brideknl@gmail.com

\section{A. K. Das}

Department of Endocrinology and Medicine, Pondicherry Institute of Medical Sciences, Puducherry, India

\section{P. Baruah}

Department of Endocrinology, Excel Hospital, Guwahati, Assam, India

\section{A. G. Unnikrishnan}

Department of Endocrinology and Diabetes, Chellaram Diabetes Institute, Pune, Maharashtra, India

\section{A. Dasgupta}

Department of Endocrinology, Rudraksh

Superspecialty Care, Siliguri, India associated with diabetes mellitus (DM) and its management.

Background: Diabetes mellitus is a metabolic syndrome characterized by diverse biomedical and psychosocial features. Emotional health disturbances may lead to psychological and psychiatric dysfunction and may negatively influence glycemic control. Patients with DM

\section{P. Shah}

Department of Endocrinology and Diabetes, Gujarat Endocrine Centre, Ahmedabad, India

R. Sahay

Department of Endocrinology, Osmania Medical College, Hyderabad, India

R. Shukla

Department of Endocrinology, Regency Hospital Ltd., Kanpur, India

S. Das

Department of Endocrinology, Apollo Hospitals, Bhubaneswar, India

M. Tiwaskar

Department of Diabetology, Shilpa Medical Research Centre, Mumbai, India

G. Vijayakumar

Department of Diabetology, Apollo Hospitals, Chennai, India 
may experience diabetes distress (DD) associated with burden of self-care, interpersonal issues, and emotional worries regarding the ability to cope with the illness. Euthymia or a state of positive mental health and psychological well-being should be considered a key outcome of diabetes care. Therefore, to achieve optimal outcomes, the consideration and measurement of psychological and psychiatric aspects along with glycemic levels are very important. A group of multidisciplinary clinical experts came together in an international meeting held in India to develop a workable concept for euthymia in diabetes care. A multidisciplinary approach was suggested to enhance the clinical outcomes and facilitate patient-centered care. During the meeting emphasis was given to the concept of a euthymia model in diabetes care. This model focuses on enhancement of self-care skills in diabetic patients and preventative health awareness among diabetes care providers. Euthymia also encompasses patient-provider communication to aid enhancement of coping skills.

M. Chawla

Department of Diabetology, Lina Diabetes Care and Mumbai Diabetes Research Centre, Mumbai, India

F. Eliana

Department of Internal Medicine, Faculty of

Medicine, YARSI University, Jakarta, Indonesia

K. Suastika

Indonesian Association of Endocrinology, Jakarta, Indonesia

A. Orabi

Department of Internal Medicine, Faculty of Medicine, Zagazig University, Zagazig, Egypt

A. A. A. Rahim

Department of Diabetes and Metabolism,

Alexandria University, Alexandria, Egypt

A. Uloko

Department of Medicine, Aminu Kano Teaching

Hospital, Kano, Nigeria

\section{R. Lamptey}

Department of Family Medicine, Korle Bu Teaching

Hospital, University of Ghana, School of Public

Health Ghana, Accra, Ghana

N. Ngugi

Department of Internal Medicine and Diabetes,

Kenyatta National Hospital, Nairobi, Kenya
Results: After due discussions and extensive deliberations, the expert group provided several recommendations on implementing the concept of euthymia in DM care.

Conclusions: Introduction of the concept of euthymia in routine clinical practice is important to improve the quality of life and coping skills in patients with DM. A timely clinical assessment of psychological and psychiatric aspects along with patient-reported outcomes of diabetes contributes to overall health and wellbeing of affected individuals.

Funding: Sanofi India.

Keywords: Diabetes distress; Diabetes mellitus; Euthymia; Psychological; Stress

\section{INTRODUCTION}

Diabetes mellitus (DM) has a profound impact on both the physical and mental well-being of the affected individual. Management of DM is multifaceted. In addition to accepting prescribed

S. Bahendeka

Department of Internal Medicine, Diabetes and Endocrinology, St. Francis Hospital, Nsambya, Kampala, Uganda

A. A. Abdela

Department of Internal Medicine, Addis Ababa

University, Addis Ababa, Ethiopia

F. Mohammed

Department of Endocrinology of Bangabandhu Sheikh, Mujib Medical University, Dhaka, Bangladesh

Mohammed FaruquePathan · F. Afsana Department of Endocrinology, Bangladesh Institute of Research and Rehabilitation for Diabetes, Endocrine and Metabolic Disorders (BIRDEM), Dhaka, Bangladesh

M. H. Rahman

Department of Endocrinology, Dhaka Medical College and Hospital, Dhaka, Bangladesh

S. Selim

Department of Endocrinology, Bangabandhu Sheikh Mujib Medical University, Dhaka, Bangladesh

M. Moosa - M. Murad

Department of internal Medicine, Indira Gandhi

Memorial Hospital, Malé, Maldives 
pharmacotherapy, patients with DM have to follow physician's advice with regards to non-pharmacologic interventions focusing mainly on lifestyle changes. Facing additional responsibilities of self-monitoring and adherence to the marked readjustment in lifestyle factors entail a fair amount of stress [1]. Diabetes mellitus is linked to a high burden of psychiatric morbidity, whereas depression and anxiety are worsened by hyperglycemia. Therefore, in DM patients, in addition to the evaluation of glycemic levels, measurement of distress, depression, and anxiety is crucial to achieve optimal outcomes. Learning and maintaining self-management, coping skills, disease progression, and onset of complications may also precipitate psychological issues in most of patients with DM [2].

Some mental health disorders, such as anxiety and depression, are more prevalent in DM patients, whereas certain conditions, such as diabetes distress (DD) and insulin distress, are very specific to the disease per se. Diabetes distress can be explained as an emotional worry that forms a part of the spectrum of patients' feelings and experiences during the management of DM. Diabetes distress is defined as an emotional

P. K. Shreshtha

Department of Internal Medicine, Tribhuwan

University Teaching Hospital, Kathmandu, Nepal

D. Shreshtha

Department of Endocrinologist, Norvic

International Hospital Kathmandu, Kathmandu, Nepal

M. Giri

Department of Endocrinology, Nepal Mediciti

Hospital, Kathmandu, Nepal

W. Hussain

Department of Endocrinology \& Diabetes, Dr Wiam Clinic, Royal Hospital, Awali Hospital, Awali,

Bahrain

A. Al-Ani

Department of Internal Medicine, Hamad Hospital, Doha, Qatar

K. Ramaiya

Department of Diabetology, Shree Hindu Mandal

Hospital, Dar es Salaam, Tanzania

S. Singh

Department of Internal Medicine, Aster Al Raffah

Hospital, Muscat, Oman response characterized by extreme apprehension, discomfort, or dejection due to perceived inability to cope with the challenges and demands of living with diabetes [3]. As DD is a common occurrence in DM patients, healthcare professionals should identify the cause for DD and minimize its impact on the affected person.

The concept of euthymia is not confined only to patients with diabetes; euthymia is applicable to diabetes care providers as well, as they are constantly under stress due to work pressure. It is important for healthcare providers to adopt preventive health strategies to achieve overall health and well-being.

Patient-provider communication constitutes an integral part of the euthymia model in diabetes care. Effective communication between the patient and provider is crucial to aid the motivational interview with the patient and also to promote enhancement of coping skills in the patient.

\section{METHODS}

At the international meeting, the experts reviewed the available literature evidence and

\author{
S. A. Raza \\ Department of Endocrinology, Shaukat Khanum \\ Hospital and Research Center, Lahore, Pakistan \\ T. T. Aye \\ Myanmar Society of Endocrinology and \\ Metabolism, Yangon, Myanmar \\ C. Garusinghe \\ Department of Endocrinology, Colombo South \\ Teaching Hospital, Colombo, Sri Lanka \\ D. Muthukuda \\ Department of Endocrinology, Sri Jayawardenapura \\ General Hospital, Sri Jayawardenapure Kotte, Sri \\ Lanka \\ M. Weerakkody \\ Department of Endocrinology, Teaching Hospital \\ Karapitiya, Galle, Sri Lanka \\ S. Kahandawa \\ Department of Endocrinology, District General \\ Hospital, Matara, Sri Lanka \\ C. Bavuma \\ College of Medicine and Health Science, University \\ of Rwanda, Kigali, Rwanda
}


provided their individual insights based on clinical experience in the management of DM. The primary focus areas of this international meeting were $\mathrm{DD}$, psychological burden in diabetes, and physician's workload in diabetes care. The panel's key discussion points were based on scientific evidence and collective clinical judgment from practice. These key discussion points considered as "clinical expert opinions" were developed for the topics mentioned above and have been summarized in this statement. This article is based on previously conducted studies and does not contain any studies with human participants or animals performed by any of the authors.

\section{RESULTS}

\section{Euthymia in Patients with DM (DD)}

\section{Understanding the Concept of Euthymia in Diabetes}

Euthymia refers to optimal mental state or mood and is an essential part of good health and wellbeing. The word euthymia ("eu" = well + "thymos" $^{\prime \prime}$ soul/emotion) was first defined by the Greek scholar Democritus as "one is satisfied with what is present and available, taking little heed of people who are envied and admired and observing the lives of those who suffer and yet endure." Euthymia could be broadly described as a state of positive mental health, eustress, and psychological well-being [4].

Euthymia should be considered as an important tool and target in diabetes care, as

\author{
S. Ruder \\ Department of Endocrinology and metabolism, \\ Charlotte Maxeke Johannesburg Academic Hospital, \\ Johannesburg, South Africa \\ K. Vanny \\ Department of Diabetes and endocrinology, Dr \\ KoyVanny Diabetes \& Endocrine Clinic, Phnom \\ Penh, Cambodia \\ M. Khanolkar \\ Department of Endocrinology and Diabetes, \\ Waikato Hospital, Hamilton, New Zealand \\ L. Czupryniak \\ Department of Diabetology \& Internal Medicine, \\ Medical university of Warsaw, Warsaw, Poland
}

the burden of mental health dysfunction is high in DM patients. Mental health dysfunction and hyperglycemia have a bidirectional relationship. Euthymia delivers a sense of healthy life and healthy coping with diabetes. The concept of euthymia emphasizes the ability to identify and acclimatize to various situational demands in diabetes management. Euthymia highlights the importance of maintaining adequate balance among important life domains and to display compatibility in one's behavior throughout the course of the DM management (Fig. 1) [4].

\section{Redefining Diabetes Distress}

As discussed earlier, emotional worries that form a part of the spectrum of patients' feelings and experiences during the management of chronic diseases, such as DM, over time, are defined as diabetes distress. The clinical expert group, however, relooked into the definition of DD. Diabetes distress was redefined as persistent emotional burden or worries that form a part of the spectrum of patients' feelings and experiences during the management of chronic disease such as diabetes mellitus, over time [1].

\section{Prevalence of DD}

A large proportion of research in the literature takes into consideration both type $1 \mathrm{DM}$ (T1DM) and type 2 DM (T2DM) when exploring the prevalence of DD. However, this approach may not be appropriate to define DD, as the emotional concerns may differ in patients with T1DM compared to those with T2DM. A metaanalysis by Perrin et al. evaluated the overall prevalence of DD in patients with T2DM. The meta-analysis included 55 studies with 36,998 T2DM patients. The overall prevalence of DD was calculated to be $36 \%$ in T2DM patients. The meta-analysis also reported a significantly higher prevalence of DD in samples with a higher prevalence of comorbid depressive symptoms and female sample majority [5].

\section{Time Points in DM Patients Associated with Increased Levels of DD}

At some point during the diabetes trajectory all patients experience distress. It is important to 


\section{EUTHYMIA MODEL}

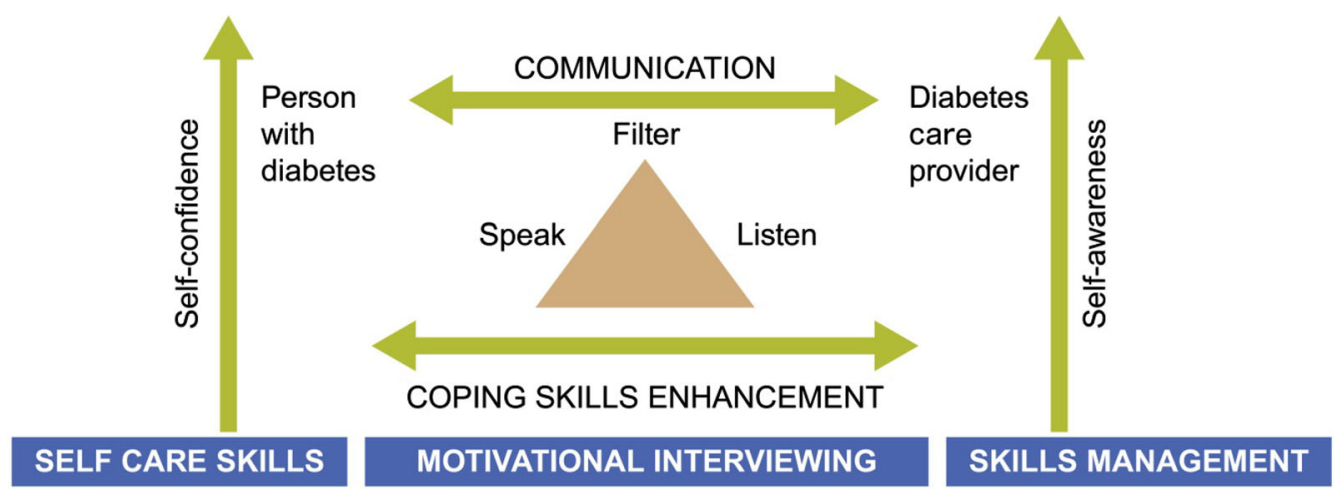

Fig. 1 Proposed model for achieving euthymia in diabetes care

identify the periods during which the level of distress is at its peak. Some of the identifiable periods during which the probability of having high levels of distress include:

- Around the time of diagnosis of DM

- At the time of learning how to self-manage DM

- At the emergence of complication

- At the time of switching medications and healthcare plans

- At the time of switching healthcare providers [6]

\section{Differentiating DD and Clinical Depression}

Unlike clinical depression, DD is persistent over time, associated with glycemic control and disease management, and expressed in terms of magnitude and content. Content refers to the factors that are associated with feelings of distress, such as diet control, strain, or social relationships. Severity or magnitude refers to the extent to which the patient experiences these feelings [7].

For a patient to be diagnosed with clinical depression, five or more of the symptoms mentioned below need to be present for a period of at least 2 weeks, representing a significant change from baseline functioning. The symptoms include depressed mood, diminished interest/pleasure in daily activities, change in appetite, insomnia or hypersomnia, psychomotor agitation or retardation, fatigue, feeling of worthlessness or guilt, and diminished concentration. In contrast, DD encompasses a wide range of emotional responses that differ from one patient to another and include any of the following responses: feeling unmotivated, burned out, overwhelmed, frustrated, angry, guilty, fear (of hypoglycemia or complications), or lonely [8].

Several different measures are used for the assessment of clinical depression and DD in DM patients in clinical practice and research. The most commonly used measures for screening clinical depression in DM patients are the Diagnostic and Statistical Manual of Mental Disorders Criteria for Major Depressive Disorders, Patient Health Questionnaire 9, and Center for Epidemiological Studies Depression Scale. Unlike CD, measurement of DD in patients with DM is context-specific and more straightforward. Some of the most commonly used screening measures include Problem Areas in Diabetes (PAID), Diabetes Distress Scale (DDS), and GlucoCoper [7].

\section{Screening and Diagnosis of DD}

Several self-reported measures, such as ATT39, Questionnaire on Stress in Patients with Diabetes-Revised (QSD-R), and PAID Scale, are used to assess the nature and extent of DD. These are used as screening measures for clinical and research purposes. However, these measures have some limitations [9]:

- Some of the measures do not cover a few critical areas of interest adequately. For instance, in PAID there is only one item that 
addresses the patients' feelings about their healthcare provider.

- In some measures, the items may be confusing for the patient. For example, in QSD-R, one item reads, "I suffer from irritability," but this may be difficult for the patients to comprehend.

- Measures such as ATT39, QSD-R, and PAID have established subscales, which are not brief.

- Certain critical areas of interest are not covered by these measures [9].

Therefore, the DD scale was developed to address all these limitations. The DD scale aids in identification of the major sources of distress, which include powerlessness, negative social perceptions, physician's distress, friend or family distress, hypoglycemia distress, management distress, and eating distress [6].

1. The 2-item DD screening scale

The 2-item DD scale is a screening measure that aids in the assessment of two potential problem areas that patients with DM may experience. The scale aids in assessment of the level of distress with regard to these two items in a patient during the past month. The patient is required to circle the items based on the severity of the symptoms suggested in the scale $[10,11]$.

2. The 17-item DD screening scale

The 17-item DD scale lists the 17 potential problem areas that a patient with T2DM may experience. Patients are required to consider the degree or level to which each of the items included in the scale may have distressed him/her during the past 1 month and then to circle the appropriate number $[10,11]$.

\section{Management of DD}

1. Diabetes therapy by ear

The four important aspects of the management of DD include strengthening of selfcare skills, optimization of coping skills, minimizing the discomfort associated with change, and utilization of support from other stakeholders. It is important to note that all these interventions are non-pharmacological and are purely based on patient-provider conversation and communication. Therefore, this management approach is termed diabetes therapy by ear [12].

2. Focused treatment approach

A focused treatment approach specifically targets the following four areas in DD [12]:
(a) Emotional burden
(b) Physician-related distress
(c) Regimen-related distress
(d) Interpersonal distress

3. Helping patients cope with distress Physicians should listen to patients and identify the underlying feelings that can drive distress and influence management. Some practical approaches include:

(a) Helping patients talk about their experience of diabetes

(b) Identifying the specific sources of their distress

(c) Normalizing these feelings

(d) Helping patients cope with distress as part of a regular diabetes care [6]

Key recommendations of the international multidisciplinary expert group

DD was redefined as an emotional response characterized by extreme apprehension, discomfort, or dejection due to a persistent perceived inability to cope with the challenges and demands of living with diabetes

Diabetes care professionals must work to identify the cause or etiopathogenesis of DD and minimize its impact

The 17 -item DD screening scale must be preferred over the 2-item DD scale. An appropriate time interval for DD evaluation should be determined. The physician should take responsibility to identify the risks of DD and should provide adequate counseling to a patient, instead of referring the patients to other specialists 
Table a continued

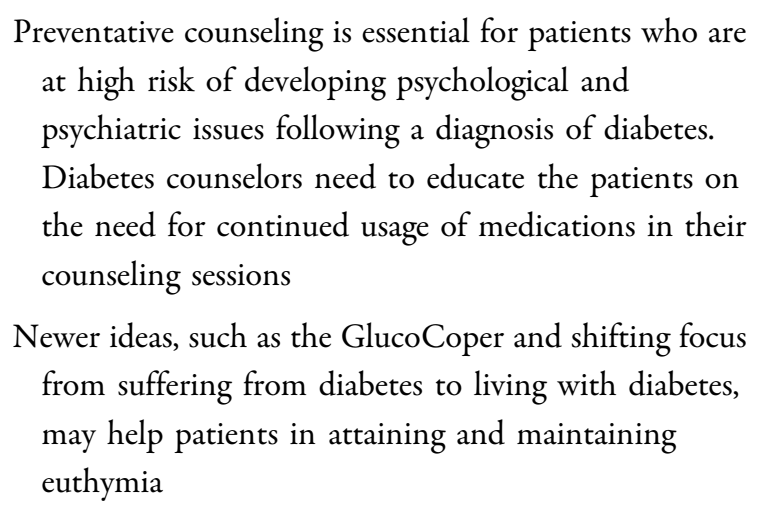

\section{Physicians' Euthymia}

\section{Background: Importance of Health and Well-} Being of the Healthcare Practitioners

Healthcare practitioners (HCPs) are exposed to significant health-related risks owing to their profession, many of which remain largely unrecognized by the public and may be underestimated by the professionals themselves. A few of these risks include fatigue, emotional/ psychological trauma, physical injury caused by the use of machinery, back injuries, and possible physical assault from a patient or a hospital visitor. Also, there are other risks that are acquired in the course of time, such as physical damage caused by the prolonged use of toxic substances and infectious diseases acquired as a result of air-borne pathogens and needle-stick injuries [13].

The three major health hazards that contribute to the ill health of a HCP include:

1. Work-related stress and burnout

2. Mental health disorders such as depression

3. Substance abuse [14]

Excessive job stress and workload are associated with negative personal and professional consequences for the physicians. Physicians who are physically and emotionally stressed out may suffer from several fears, failures, and even death (due to suicidal tendency). They have an increased risk of burnout that often culminates in difficult interactions with their families and other medical personnel. In some instances, burnout may also result in percutaneous needlestick injuries, motor vehicle crashes, or nearmiss incidents while driving. Excessive work stress and burnout may also have serious outcomes in the wellness of the physicians. They may indulge in substance abuse or may face relationship troubles, depression, or death. In addition, burnout may lead to job and career turnover (increased probability of changing jobs within medicine or abandoning the practice of medicine entirely, increased absenteeism, and interest in early retirement) [15].

\section{Adverse Health Conditions Experienced by HCPs}

(a) Chronic diseases among HCPs Physicians may develop chronic diseases due to workrelated stress and depression. The actual prevalence of chronic illness in HCPs is often under-reported because most of the physicians just adapt and carry on, even before accepting their illnesses. Also, with the awareness of their inabilities and limitations, most physicians with chronic illness are at risk of depression [16].

(b) Anxiety and depression among HCPs Physicians experience higher rates of anxiety and depression than the general public. The prevalence rates of depression or depressive symptoms vary from $3 \%$ to $60 \%$, depending on the region of study and other study factors (such as specialty, postgraduate year, and sex) [17].

(c) Burnout among HCPs Chronic exposure to stress may lead to burnout, a term commonly used to describe the emotional exhaustion experienced by workers in public services. Burnout among doctors is a global phenomenon. Apart from adversely affecting the health outcomes of the HCPs, burnout can also lead to poor quality of care delivered to patients, increased medical errors, and poor retention [18].

\section{Important Lifestyle Changes Required to Enhance Overall Health of HCPs}

Physicians should pay attention to preventive healthcare and their lifestyle behaviors to enhance their overall health. An increased focus 
on healthy daily living among physicians could help prevent the progression to serious health issues, including mental health problems and addiction. Healthcare professionals should prioritize health aspects, such as nutrition, exercise, sleep, and self-care, along with professional demands, as these can affect the physician's health on a daily basis [14].

(a) Nutrition Physicians should maintain a proper nutritional diet high in fruits, vegetables, and unprocessed whole foods. Physicians who eat a healthy diet are more likely to counsel their patients about the importance of proper nutrition. Furthermore, a healthy diet may minimize emotional symptoms, such as irritability and frustration, and physical symptoms, such as light-headedness, tremor, and nausea. It may also impact the cognitive effects (difficulty in concentrating and poor/slow decision-making) [14].

(b) Exercise Regular exercise allows the doctors to stay fit and serve as healthy role models in their community. Simple initiatives toward regular exercises, such as modifications to the workplace that promote workouts, installing secure bike racks, having shower facilities on-site for those who exercise before work or during their lunch break, and encouraging team entries to events such as local walk/runs, may instill healthy habits in HCPs [14].

(c) Sleep Sleep deprivation may both acutely and chronically affect the doctor's health. It was estimated that nearly half of the general practitioners report sleep difficulties, and almost two-thirds complain of exhaustion or sleepiness at least 3 days per week. Steps that would minimize sleep deprivation include allocating duty hour limits and allowing every physician to get at least $4 \mathrm{~h}$ of constant "anchor sleep" (a consistent 24-h cycle of sleep and wakefulness to reduce fatigue) [14].

(d) Self-care Physicians usually deny or avoid personal medical problems. Most physicians refuse to seek help, even though they may realize the need for it. Furthermore, HCPs rely on self-prescribing medications in case of personal health issues, a practice that is considered unethical by all medical associations. It is therefore essential that all the physicians have their own general physician (GP) who can provide regular, continual, and effective healthcare. This practice would avoid the issue of selfprescribing and ensure that physicians are taking the recommended preventive screening measures [14].

\section{Barriers to Healthy Preventative Habits among HCPs}

Doctors often experience barriers while accessing healthcare, which they ought to overcome in order to improve their physical and mental health. The barriers may be divided into three categories [19]:

(a) The "Patient" category that reflects the barriers specifically related to the doctorpatient seeking healthcare

(b) The "Provider" category that reflects the barriers that are under the control of the medical care provider

(c) The "Platform (or System)" category that reflects barriers within the medical system itself [19]

\section{Stress Management Strategies to Improve Health Status of HCPs}

Several creative approaches have been evolved in recent years to address the rising problem of burnout. Initially, in 2007, Politsky et al. [20] developed a program involving verbalization of patients (making the patients verbalize their inner feelings) accompanied by various relaxation techniques, such as music, yoga, meditation, affirmations, and therapeutic messages. Italia et al. [21] studied art therapy as a treatment for burnout in an oncology unit. They found a statistically significant decrease in the burnout level after participation in the art therapy interventions. Studies by Dileo et al. [22] and Repar et al. [23] confirmed that the use of massage, yoga, art, music, and writing helped in reducing stress and depression in medical professionals. Massage with aromatherapy and music for stress reduction in nurses was studied by Cooke et al. [24]. 
Brooks et al. investigated the effects of music imagery (creation of mandalas) on self-reported burnout, sense of coherence, and job satisfaction in medical professionals. Qualitative results suggested that the music imagery helped the subjects relax, rejuvenate, and refocus, enabling them to complete their shifts with renewed energy [25].

Key recommendations from the international expert group

HCPs are exposed to significant health risks by virtue of their profession. Many of these health hazards remain largely unrecognized by the public and may be underestimated by the professionals themselves

Physicians should develop a structured lifestyle to overcome health hazards. A structured program for bringing in lifestyle changes that are visible, practical, and possible can help physicians cope with the possibility of burnout

A small gym or recreation corner in the clinic may help physicians overcome stress

Medical students and postgraduates should be made aware of the pitfalls of hospital and clinical practice

Work-life balance and synchronization can help improve happiness quotient among the physician community. This can be achieved if physicians can get involved in diverse aspects of patient care, such as technological innovations and patient advocacy programs

\section{Partnership Euthymia}

\section{Concept of Partnership Euthymia}

Patient-healthcare provider communication plays an integral role in diabetes care. In clinical practice, euthymic diabetes conveys a positive aura and could be used to nullify DD. Therefore, patient-provider communication should be more focused on achieving diabetes euthymia, rather than discussions targeted to avoid DD. This concept of partnership euthymia emphasizes the importance of the biopsychosocial model of health, rather than a purely glucocentric or biomedical approach.

\section{Background: Need for Striking Smart Conversations with DM Patients: When and How?}

Striking smart conversations with the patients is necessary throughout the course of the disease, but is especially important when:

- Diabetes is first diagnosed

- Inappropriate self-care behaviors occur

- Conflicts arise between belief systems and therapies

- Insulin therapy becomes necessary

- Cardiovascular risk is increased

- Sexual dysfunction (SD) occurs [26]

The tools for striking smart conversations in the above scenarios include:

(a) Patient-centered clinical methods These methods are performed by exploring the disease as well as illness experiences-fears, feelings, functionality, expectations (FIFE); understanding the whole person; finding common ground; incorporating preventive health-maintenance services; enhancing the patient-doctor relationship; and being realistic [26].

(b) Biopsychosocial model A biopsychosocial model is a combination of the psychological, social, and biological aspects of health. The biopsychosocial model takes into account the patient, the social context in which he lives, and also the role of the physician and the healthcare system in dealing with the effects of the illness. The sociological and psychological factors can have an influence on patients' adherence to treatment. As societal, psychological, and biological factors can individually or collectively impact disease morbidity, the biopsychosocial model should be considered an appropriate tool for striking smart conversations [26].

(c) Wagner's chronic care model

(d) Motivational interviewing

\section{Striking Conversations with DM Patients about $S D$}

Sexual dysfunction is widespread in diabetic patients, and, most often, patients with SD tend to suffer in silence. The common SDs include 
erectile dysfunction, diminished sexual desire, lack of ejaculation with sexual climax (an ejaculation or retrograde ejaculation), and premature ejaculation. Very few patients approach their diabetologists to discuss these issues. Male SD (MSD) can be manifestations of biological (biogenic) problems or intra-psychic or interpersonal (psychogenic) conflicts or even a combination of these factors. Stress plays an important role in the pathogenesis of MSD. In fact, a good doctor-patient rapport is crucial to make patients more comfortable and open to talk about their sexual function [27].

Physicians must use their experience to make patients comfortable and free to discuss their problems without any inhibition. Irrespective of the magnitude of the problem, physicians must address the need of the patients with courtesy and empathy. Physicians must work toward providing solutions within the ethnic and cultural framework of the patients. Physicians must provide a calm and relaxed atmosphere for patients to discuss their problems. Each relevant aspect of history should be explored in detail. At all times, the five E's of sexual history taking, i.e., empathy, etiquette, experience, ethnic/cultural understanding, and environment conducive for relaxation, must be followed [28].

Physicians should interview patients with general questions, and then consider questions related to the distant past before inquiring about present complaints-physicians should begin with questions related to adolescent fantasies, and enquire about any premarital sexual contact, experiences, and difficulties, before probing into the current marital sexuality. During taking the sexual history, probing questions on non-genital aspects should be considered before enquiring about genital issues. Questions directed toward the present medical history should focus on non-sexual symptoms (i.e., symptoms suggestive of skin infection or urinary tract infection) before probing sexual function-related concerns [28].

\section{Important Aspects of Counseling in MSD}

Counseling is an integral part of diabetes management, but is not fully utilized in clinical practice. Physicians must utilize all the available resources and sharpen their counseling efficiency. A few attributes are essential to the success of a high-quality counseling service [29].

CARES is a pneumonic, which describes the basic qualities necessary to successfully manage MSD:
C Confident competence
A Accessible authenticity
$\mathrm{R}$ Reciprocal respect
E Expressive empathy
S Straightforward simplicity

\section{Counseling Methods in Patients with MSD}

A healthy diet forms an important part of counseling for MSD. Physicians/counselors must encourage patients with MSD to eat a balanced diet rich in vitamins and minerals, supplemented by nutraceuticals if necessary. Avoidance of smoking and moderation of alcohol intake are essential points for discussion [28].

Sexual fitness will be achieved only if one is physically fit, and attention should be paid to the aspects of physical health that may impair sexual function, such as obesity, musculoskeletal weakness, lack of flexibility, and other medical conditions. Patients should be encouraged to indulge in moderate physical activity at least three times a week [28].

Training in coping skills should form a part and parcel of each counseling session on MSD. This training includes inculcating positive mechanisms and avoiding negative mechanisms of coping [28].

Patients who do not respond to non-pharmacological and conventional pharmacological therapy may need to be treated with various devices, invasive procedures, or surgery. Patients who may need these treatments must be explained about the need for such therapy well in advance, which would encourage them to stick to their decision regarding the choice of treatment and proven post-device or post-surgical regret [28].

\section{Striking Conversations with DM Patients About CV Risk}

Effective individualized cardiovascular disease (CVD) risk communication can be constructed around several general principles. Patients want practical, concise information focused on the 
identification of the problem, what specifically they need to do, why it is in their best interest, and what outcomes they can expect. The following methods may be employed to create awareness among patients [27]:

- Graphic illustration of the atherosclerotic process using simple language, diagrams, and analogies

- Graphic description of the consequences of a CVD event, e.g., pain, disability, and death, as possible consequences of a myocardial infarction

- Use of risk calculators to predict the current risk of CVD

- Provide optimal therapeutic regimen

- Shared decision-making to develop a treatment plan [30]

Personal CVD risk is a fundamental component of the overall CVD risk message; however, many patients do not reliably understand and interpret numerical probability of risk. The risk must be potentially conveyed to patients in terms of high, moderate, or low risk [30].

Mental and emotional engagements can be encouraged through interactive multimedia presentations in the forms of video, graphics, animation, sound, and text. Interactive technology may be effective in addressing the issues of limited health literacy [30].

\section{Important Messages to Reinforce While Striking Smart Conversations}

1. Promote healthy lifestyle

A healthy lifestyle is key to diabetes control, and hence physicians need to talk to patients about lifestyle choices [31].

- Advise people with diabetes to aim for a healthy weight.

- Encourage meal planning that includes a variety of foods, controlled portion sizes, and snacks. Increasing fiber and limiting refined carbohydrates, salt, and fat will help control blood glucose, blood pressure, and cholesterol.

- Advise people with diabetes to include moderate-intense physical activity (such as brisk walking) in their daily life.
- Ask people with diabetes to identify their high-priority concerns or goals. Prompt them to plan for challenging situations and set short-term achievable goals.

- People with diabetes need to avoid smoking and using smokeless tobacco products [31].

2. Support self-care behaviors

Support self-care behaviors such as:

- Daily foot care

- Eye care

- Daily oral care: brush and floss

- Monthly oral self-exam

- Selection and use of a blood glucose monitor as needed

- Knowledge of your ABC goals and how to reach them

- Use of medications as prescribed [31]

3. The longer the counseling, better the treatment adherence

Physicians can tackle the adherence problem through quality patient counseling. Enhancing communication between the physician and the patient is a key and effective strategy in boosting the patient's ability to follow a medication regimen. The ask-educate-ask approach, teach-back method, and motivational interviewing can help ensure patient understanding of the counseling provided. A study described that a significant proportion of patients who were non-adherent to treatment prior to counseling became adherent after proper counseling [32].

Key recommendations from the international expert group

According to the expert group, a good doctor-patient rapport is crucial to make patients more comfortable and open to talk about their sexual problems

In all newly diagnosed diabetic patients, physicians need to enquire about any SD in last 3 months 
Table c continued

Approach to patient during assessment for SD should
be systematic, from non-threatening to threatening
questions
Diabetes mellitus patients with a favorable response to
assessment should be referred for further evaluation
and care to a specialist
In this context, the clinical expert group came up with
recommendations for appropriate timing for
assessment of SD in male and female DM patients
The team also suggested that a protocol for MSD and
female SD assessment should be implemented in
clinical practice

\section{CONCLUSION}

Psychiatric disorders, such as anxiety and depression, occur with greater frequency in patients with DM. Additionally, DM patients are at an increased risk of developing DD and insulin distress, which can influence clinical outcomes. Introduction of the concept of euthymia in routine clinical practice is important to improve quality of life and enhance coping in patients with DM. Implementation of a euthymic model of care promotes well-being of both patient and diabetes care provider.

\section{ACKNOWLEDGEMENTS}

We acknowledge Shalini Menon, Senthilnathan Mohana Sundaram, Romik Ghosh and S. Amarnath from Sanofi India for their logistics assistance, guidance and expertise in convening an expert forum meeting. The content published herein represents the views and opinions of the various contributing authors and does not necessarily represent the views or opinion of Sanofi and/or its affiliates. The details published herein are intended for informational, educational, academic and/or research purposes and are not intended to substitute for professional medical advice, diagnosis or treatment.

Funding. This expert opinion initiative has been funded by Sanofi India. The article processing charges received by the journal were paid for by Sanofi India. All authors had full access to the articles reviewed in this manuscript and take complete responsibility for the integrity and accuracy of this manuscript.

Medical Writing and Editorial Assistance. Medical writing and editorial support was provided by Dr Rajshri Mallabadi and Dr Kavitha Ganesha from BioQuest Solutions Pvt. Ltd. which was paid for by Sanofi, India.

Authorship. All named authors meet the International Committee of Medical Journal Editors (ICMJE) criteria for authorship for this article, take responsibility for the integrity of the work as a whole, and have given their approval for this version to be published.

Disclosures. Sanjay Kalra is a member of the journal's Editorial Board. A. K. Das, M. P. Baruah, A. G. Unnikrishnan, Arundhati Dasgupta, Parag Shah, Rakesh Sahay, Rishi Shukla, Sambit Das, Mangesh Tiwaskar, G. Vijayakumar, Manoj Chawla, Fatimah Eliana, Ketut Suastika, Abbas Orabi, Aly Ahmed Abdul Rahim, Andrew Uloko, Roberta Lamptey, Nancy Ngugi, Silver Bahendeka, Abdurezak Ahmed Abdela, Fariduddin Mohammed, Faruque Pathan, Muhammed Hafizur Rahman, Faria Afsana, Shajada Selim, Muaz Moosa, Moosa Murad, Pradeep Krishna Shreshtha, Dina Shreshtha, Mimi Giri, Wiam Hussain, Ahmed Al-Ani, Kaushik Ramaiya, Surender Singh, Syed Abbas Raza, Than Than Aye, Chaminda Garusinghe, Dimuthu Muthukuda, Muditha Weerakkody, Shyaminda Kahandawa, Charlotte Bavuma, Sundeep Ruder, Koy Vanny, Manish Khanolkar and Leszek Czupryniak have nothing to disclose.

Compliance with Ethics Guidelines. This article is based on previously conducted studies and does not contain any studies with human 
participants or animals performed by any of the authors.

Open Access. This article is distributed under the terms of the Creative Commons Attribution-NonCommercial 4.0 International License (http://creativecommons.org/licenses/ by-nc/4.0/), which permits any noncommercial use, distribution, and reproduction in any medium, provided you give appropriate credit to the original author(s) and the source, provide a link to the Creative Commons license, and indicate if changes were made.

\section{REFERENCES}

1. Berry E, Lockhart S, Davies M, et al. Diabetes distress: understanding the hidden struggles of living with diabetes and exploring intervention strategies. Postgrad Med J. 2015;91(1075):278-83.

2. Young-Hyman D, de Groot M, Hill-Briggs F, et al. Psychosocial care for people with diabetes: a position statement of the American Diabetes Association. Diabetes Care. 2016;39(12):2126-40.

3. Kalra S, Verma K, Singh Balhara YP. Management of diabetes distress. J Pak Med Assoc. 2017;67(10):1625-7.

4. Kalra S, Singh Balhara YP, Bathla M. Euthymia in diabetes. Eur Endo. 2018;14(2):18-19.

5. Perrin NE, Davies MJ, Robertson N, et al. The prevalence of diabetes-specific emotional distress in people with type 2 diabetes: a systematic review and meta-analysis. Diabet Med. 2017;34(11):1508-20.

6. Fisher L, Snouffer E. Diabetes distress: a real and normal part of diabetes. Expert Interview. 2016. https://www.idf.org/component/attachments/ attachments.html?id=594\&task=download. Accessed 30 Dec 2017.

7. Fisher L, Gonzalez JS, Polonsky WH, et al. The confusing tale of depression and distress in patients with diabetes: a call for greater clarity and precision. Diabet Med. 2014;31(7):764-72.

8. Kreider KE. Diabetes distress or major depressive disorder? A practical approach to diagnosing and treating psychological comorbidities of diabetes. Diabetes Ther. 2017;8(1):1-7.

9. Polonsky WH, Fisher L, Earles J, et al. Assessing psychosocial distress in diabetes: development of the diabetes distress scale. Diabetes Care. $2005 ; 28(3): 626-31$.

10. Fisher L, Glasgow RE, Mullan JT, et al. Development of a brief diabetes distress screening instrument. Ann Fam Med. 2008;6(3):246-52.

11. The Diabetes Distress Screening Scale. http://www. diabetesed.net/page/_files/diabetes-distress.pdf. Accessed 29 Dec 2017.

12. Kalra S, Verma K, Singh Balhara YP. Management of diabetes distress. J Pak Med Assoc. 2017;67(10):1625-7.

13. Treanor HL. Health risks and the health care professional. Med Health Care Philos. 2000;3(3):251-5.

14. Tysuk K. Physician health: a review of lifestyle behaviors and preventive health care among physicians. BCMJ. 2012;54(8):419-23.

15. Wallace JE, Lemaire JB, Ghali WA. Physician wellness: a missing quality indicator. Lancet. 2009;374(9702):1714-21.

16. Gautam M, MacDonald R. Helping physicians cope with their own chronic illnesses. West J Med. 2001;175(5):336-8.

17. Kumar S. Burnout and doctors: Prevalence, prevention and intervention. Healthcare. 2016;4(3):37.

18. Mata DA, Ramos MA, Bansal N, et al. Prevalence of depression and depressive symptoms among resident physicians: a systematic review and metaanalysis. JAMA. 2015;314(22):2373-83.

19. Kay M, Mitchell G, Clavarino A, et al. Doctors as patients: a systematic review of doctors' health access and the barriers they experience. Br J Gen Pract. 2008;58(552):501-8.

20. Politsky S. Revitalizing yourself: making time for you. Oncology Nursing Forum. 2007;34(2):494.

21. Italia S, Favara-Scacco C, Di Cataldo A, et al. Evaluation and art therapy treatment of the burnout syndrome in oncology units. Psychooncology. 2008;17(7):676-80.

22. Dileo C, Bradt J. Medical music therapy: a metaanalysis of literature in music therapy and medicine. Jeffrey Books. 2005

23. Repar PA, Patton D. Stress reduction for nurses through arts-in-medicine at the university of New Mexico hospitals. Holist Nurs Pract. 2007;21(4):182-6. 
24. Cooke M, Holzhauser K, Jones M, et al. The effect of aromatherapy message with music on the stress and anxiety levels of emergency nurses: comparison between summer and winter. J Clin Nurs. 2007;16(9):1695-703.

25. Brooks DM, Bradt J, Eyre L, et al. Creative approaches for reducing burnout in medical personnel. Arts Psychother. 2010;37:255-63.

26. Brown JB, Stewart M, Weston WW, et al. Introduction. In: Stewart M, editor. Patient-centered medicine: transforming the clinical method, 2nd edn. United Kingdom: Radcliffe Medical Press Ltd; 2003.

27. Kalra S, Balhara YS, Baruah M, et al. Consensus guidelines on male sexual dysfunction. J Med Nutr Nutraceut. 2013;2:5-18.

28. Kalra S, Chawla R, Madhu SV. The dirty dozen of diabetes. Indian $\mathrm{J}$ Endocrinol Metab. 2013;17(3):367-9.
29. Kalra S, Kalra B. A good diabetes counsellor 'Cares': soft skills in diabetes counselling. Int J Health. 2010;11:1-4.

30. Roach P, Marrero D. A critical dialogue: communicating with type 2 diabetes patients about cardiovascular risk. Vasc Health Risk Manag. 2005;1(4):301-7.

31. Centers for Disease Control and Prevention. https://www.cdc.gov/diabetes/ndep/pdfs/ppodguide-what-to-discuss-patients.pdf. Accessed $6 \mathrm{Sept}$ 2018.

32. Mathew ME, Rajiah K. Assessment of medication adherence in type- 2 diabetes patients on poly pharmacy and the effect of patient counseling given to them in a multispecialty hospital. J Basic Clin Pharm. 2013;5(1):15-8. 